\title{
Sistemas de informação e conhecimento emancipatório
}

Eduardo Loebel

\begin{abstract}
Professor Titular do PPGA da Universidade Metodista de São Paulo. Professor da EAESP-FGV. Mestre em Administração pela EAESP-FGV. Doutor em Ciências Sociais (Sociologia) pela PUC-SP.
\end{abstract}

Vivian Iara Strehlau

Professora Titular do Departamento de Marketing da ESPM e IBMEC, São Paulo. Mestre e doutora em Administração pela EAESP-FGV.

Esse trabalho aborda o conhecimento emancipatório no campo de sistemas de informação, fundamentado em teoria crítica. Os objetivos são: descrever um método de análise dialético para a produção desse tipo de conhecimento e aplicá-lo na análise de uma ilustração empírica, utilizando um caso brasileiro. Duas metáforas emergem como resultado, evidenciando-se numa delas a possibilidade de conhecimento emancipatório na situação analisada. Nas considerações finais discute-se a adequação do método de análise dialético, suas forças e limitações observadas no decorrer da investigação.

Palavras-chaves: Sistemas de informação; Conhecimento emancipatório; Modernidade; Teoria crítica; Método de análise dialético.

\section{Information systems and emancipatory knowledge}

This paper focusses on emancipatory knowledge considering the field of information systems based on the critical theory. The objectives are: to present a dialectical method of analysis producing such knowledge and to apply it through an empirical illustration using a Brazilian case. Two metaphors emerge from the analysis and in one of them there is evidence of emancipatory knowledge. The adequacy of the dialectic method of analysis as well as strengths and limitations observed during the research are discussed. 
Keywords: Information systems; Emancipatory knowledge; Modernity; Critical theory; Dialectic method of analysis.

Recebido em 29.09.2008 Aceito em 12.03.2009

\section{Introdução}

Este artigo é um ensaio que se inspirou na tradição crítica ${ }^{1}$. Desenvolver uma reflexão sobre a inter-relação entre o campo de sistemas de informação e o conhecimento emancipatório não é assunto novo, visto que Ludmer et al (2002, p. 2) analisaram "a visão emancipatória em sistemas de informações, sob a ótica da teoria crítica de Jürgen Habermas, utilizando a sua taxionomia para classificar a produção acadêmica em SI no Brasil". Para os autores, o trabalho de Ngwenyama e Lee (1997) é um dos mais referenciados exemplos de geração de conhecimento emancipatório, com a demonstração das contribuições da teoria crítica na análise da teoria da riqueza da informação (Information Richness Theory - IRT) e das limitações das visões positivistas e interpretativas. Inspirando-nos no trabalho de Ngwenyama e Lee (1997), propomos colocar em discussão uma forma de análise dialética baseada em Benson (1977; 1983) e aplicá-la para analisar uma situação empresarial brasileira, previamente descrita por Marino, Scare e Zylbersztajn (2002).

Entendemos com Ludmer et al (2002) que o conhecimento emancipatório consiste na realização de análises crítica e dialética a partir de pressupostos teóricos e práticos. Quando aplicado ao campo de sistemas de informação, tem como finalidade questionar valores e pressupostos correntes sobre sistemas de informação e as tecnologias decorrentes de sua gestão, implementação e de sua utilização nas organizações. Portanto, os objetivos desse trabalho são: (1) descrever um método de análise dialético como forma de produzir conhecimento de interesse emancipatório no campo de sistemas de informação; (2) ilustrar o uso do método descrito utilizando dados secundários de um estudo de caso brasileiro.

O presente trabalho divide-se em seis partes. Esta introdução é a sua primeira parte. Na segunda tratamos dos conceitos de modernidade e racionalização para estabelecer a ligação com a fundamentação teórica para as discussões que sucedem. Na terceira parte apresenta-se o método de análise dialético. Na quarta apresenta-se uma ilustração, que constitui uma aplicação da noção de conhecimento emancipatório a uma situação empresarial brasileira, utilizando-se o método descrito. A quinta parte consta das considerações finais seguida pelas referências bibliográficas.

\footnotetext{
1 De acordo com Bronner (1997, p. 10), "todos os autores de mais destaque na tradição crítica, talvez precisamente por essa razão, empregaram o ensaio como veículo estilístico. 0 ensaio, com sua qualidade inerentemente inacabada é a forma lógica para gerar afirmações anti-sistêmicas e promover o exercício da reflexividade".
} 


\section{Modernidade, racionalização e conhecimento}

Sistema de informação é tido como um campo de estudo e de aplicação bastante recente. O desenvolvimento desse campo foi provocado pelo fenômeno denominado por Castells (1999) como "revolução informacional". Conforme argumenta Ludmer et al (2002, p.1), "por ter surgido inicialmente nas escolas de ciência da computação e engenharia, este novo campo de estudo tem sido profundamente influenciado pela engenharia de computação e análises de sistemas". Este pode ser um dos motivos pelos quais as reflexões críticas sobre questões sociais e políticas neste campo de estudo e de aplicação têm sido relativamente escassas, ainda que em crescimento (TURBAN; MCLEAN; WETHERBE, 2002; LAUDON; LAUDON, 2007).

Cabe, no entanto, retomar a noção de modernidade (TOURAINE, 1993, 1994; GIDDENS, 1991, 1997, 2002) e, no contexto dessa noção, o construto de matriz da racionalização (MARTUCCELLI, 1999), na tentativa de esclarecer essa lacuna de reflexões críticas no campo de sistemas de informação e de constituir o arcabouço teórico a ser empregado na discussão sobre o método de análise dialético em questão. Os autores de maior destaque na teoria crítica da Escola de Frankfurt - Horkheimer, Adorno, Marcuse e Habermas - são muito úteis nesse sentido, pois, enquanto se diferenciam em suas análises sobre a modernidade, compartilham de uma visão comum da responsabilidade de mobilizar o poder transformativo da razão para promover e guiar mudança emancipatória.

\subsection{Modernidade}

Para Touraine (1993), há uma ideologia ocidental que expressa e reforça uma concepção dominadora da modernidade e os correspondentes sistemas de regulação social empregados para levar a efeito tal ideologia. Tal concepção apregoa o triunfo da razão sobre a tradição, sendo que a secularização e o desencanto manifestam a ruptura necessária com a religião. A idéia de modernidade acarreta a substituição de Deus pela ciência no centro da sociedade, deixando as crenças e práticas religiosas para a vida privada. O Estado surge, separado da Igreja, para proteger as atividades intelectuais e separar a vida pública da vida privada. Assim, a idéia de modernidade encontra-se vinculada à idéia da racionalização expandida para a criação de uma sociedade racional, na qual a razão não comanda apenas a ciência e a técnica na sua luta contra o social e o cultural, mas também o governo dos homens e das coisas. Há outras características atribuídas pelo autor à concepção dominadora da modernidade, a saber: o universalismo vence o particularismo, a produção vence a reprodução, a libertação da classe trabalhadora e a promessa de abundância, a liberdade e a felicidade para todos. Para apoiar tal concepção, desenvolveram-se sistemas de regulação social dos atores, pelos quais a ordem social foi colocada a serviço da utilidade social, o funcionalismo foi adotado como principal escola de pensamento, a 
modernidade foi transformada numa ideologia e num instrumento revolucionário modernista visando a submissão de cada um (principalmente trabalhadores, colonizados, mulheres e crianças) aos interesses de todos (os homens ocidentais, adultos e bem-educados).

A modernidade entra em crise, o que Touraine $(1993,1994)$ denomina decomposição, pois se esgotam as forças libertadoras da modernidade, o que era visto como um fluxo incessante de mudanças. Além disso, perde-se o sentido de uma ação que não aceita outro critério a não ser o da pura racionalidade instrumental, o que representa para o autor um reducionismo da racionalidade e da racionalização. Por fim, a modernidade é entendida como instrumento de controle, integração e repressão das pessoas. O autor descreve o fenômeno da divisão da modernidade em quatro partes distribuídas ao longo de dois eixos. O primeiro eixo refere-se ao que vai do individual ao coletivo, e o segundo eixo refere-se ao ser e à mudança, determinado quadro divisões: a sexualidade e o consumo (individual), e o nacionalismo e a estratégia de empresa (coletivo). A modernidade se decompõe ao longo das quatro divisões por força da racionalidade instrumental, o que a leva à crise e à busca de saídas por caminhos que aparentemente conduziam-na à morte.

Giddens (1991, 1997, 2002) enfatiza que a modernidade é um sistema social em transformação e intrinsecamente orientado para o futuro. A natureza dinâmica da modernidade é a característica que está conduzindo o mundo, ou uma parte cada vez maior dele, para a denominada alta modernidade. A idéia de pós-modernidade é rejeitada pelo autor, pois considera o atual período como uma nova e diferente ordem de radicalização da modernidade. Para o autor, a alta modernidade, a qual estabelece para as ciências sociais uma nova agenda crítica em relação às deficiências das posições clássicas, é conseqüência de duas esferas de profundas transformações. Por um lado, o autor indica a ampla difusão das instituições modernas que se universalizam por meio do processo de globalização. Por outro, há o que o autor denomina transformação da intimidade nos contextos da vida cotidiana. Em relação a essa última esfera, afirma o autor que a transformação da intimidade pode ser entendida como o aumento de mecanismos de confiança, e que, nesse sentido, as relações de confiança estão diretamente relacionadas com a construção do eu a partir de um projeto reflexivo. Assim, o autor afirma que o mundo do início do século XXI encontra-se num período de evidente transição, onde o "nós" (pessoas que vivem no Ocidente, mais precisamente nos setores industrializados do mundo) não se refere apenas à hegemonia global européia ou ocidental, mas também ao mundo como um todo.

Para Martuccelli (1999, p. 9), o lugar comum mais freqüentemente associado à idéia de modernidade consiste em entendê-la como sendo uma interrogação sobre o tempo presente e sobre a sociedade contemporânea. Essa interrogação visa responder uma pergunta crucial: porque hoje não é mais como ontem? Porque não se pode esperar do mundo atual o mesmo tipo de resposta que dele obteve toda uma sucessão de precedentes gerações? Essas perguntas serão articuladas 
numa tal variedade de formas e de níveis de profundidade que o saldo final será que a modernidade acaba por se constituir num conceito de fronteiras tão amplas quanto indefinidas. Muitos são os temas, as abordagens, as problemáticas da modernidade.

A sociologia da modernidade - produto dessa mesma inquietude original - buscaria construir representações globais adequadas a um novo mundo social, tendo sempre presente a consciência imediata da distância existente entre essas representações e a realidade concreta daquilo que pretenderia representar. Ou seja, a perturbação inicial da condição moderna pode até se atenuar a cada novo esforço de compreensão empreendido, mas acaba por nunca se extinguir integralmente. A modernidade - instável, ambivalente, fugidia - está sempre ali, a impedir o conforto recém-extraído de explicações que tão árdua e precariamente se conseguiu articular. Seria esta, talvez, sua expressão mais verdadeira, a de nunca se extinguir como tema, por permanentemente se modificar. Aquilo que se tem como compreendido hoje é a previsão que amanhã será frustrada (MARTUCCELLI, 1999, p. 14).

A noção de modernidade tem sido considerada importante para o debate de inúmeros temas relacionados à sociedade e às organizações. Relacionado a este tema encontra-se a discussão sobre tecnologia como uma das manifestações típicas da racionalização dos tempos modernos. Sistemas de informação e tecnologia da informação inserem-se nessa discussão, tanto do ponto de vista teórico como de sua utilização prática nas organizações, abordados muitas vezes de forma crítica por autores da Escola de Frankfurt e outros. Passaremos, portanto, a apresentar considerações sobre o tema racionalização e uma das suas relações com o conhecimento, por meio das idéias de Jürgen Habermas.

\subsection{Racionalização e conhecimento}

Dada a grande amplitude de explorações sociológicas que o tema da modernidade engendra, torna-se necessária a identificação de recortes específicos para o desenvolvimento de análises mais particularizadas. 0 critério escolhido para a definição desses recortes foi o de matriz, tal como ele é apresentado por Martuccelli (1999). O autor estrutura a sua análise acerca da sociologia da modernidade a partir de três matrizes: diferenciação social, racionalização e condição moderna. A idéia de matriz deve ser aqui compreendida no sentido de fonte ou manancial, de tecido/tessitura original, de gênese. Em outras palavras, uma matriz seria a temática básica a partir da qual se desenvolve o trabalho de um conjunto de autores com inquietações que podem ser entendidas como semelhantes.

Para Martuccelli, a idéia de matriz é um instrumento de análise mais adequado porque permite acompanhar certa continuidade da reflexão histórica e da temática sobre a modernidade. Ao mesmo tempo, realça o papel ativo desempenhado por uma intuição inicial - o tema fundamental da matriz - de diversos autores em suas tentativas de conferir sentido às mudanças sociais por eles presenciadas nos distintos momentos históricos 
em que viveram. Desse modo, dentro de uma mesma matriz são vários os momentos de inflexão, e mesmo de ruptura com premissas inicialmente respeitadas. Existe proximidade temática, uma fonte comum de inquietação, mas não uma genealogia obrigatória entre os autores de uma mesma matriz. É por essa razão que o autor insiste na idéia de que a matriz é distinta da idéia de paradigma (KUHN, 2001), uma vez que os autores associados a uma mesma matriz não estão necessariamente ligados entre si pelo respeito a um conjunto de pressupostos comuns que necessariamente devam ser respeitados (MARTUCCELLI, 1999, p. 20).

A matriz da diferenciação social caracteriza-se por estudos que se propõem a entender como a sociedade se transforma, indo do simples ao complexo, do homogêneo ao heterogêneo (MARTUCCELLI, 1999, p. 30). Os autores selecionados pelo autor para essa matriz são Émile Durkheim, Talcott Parsons, Pierre Bourdieu e Niklas Luhmann.

A matriz da condição moderna tem como seu tema central a reflexão sobre os incontornáveis paradoxos e contradições da vida moderna. Aqui é reconhecido o caráter não permanente, volátil da modernidade e a busca pela estabilidade de algum entendimento da questão. "A tensão entre o essencial e o efêmero, entendida como a manifestação fenomenológica e existencial do indivíduo na modernidade está no núcleo desta matriz" (MARTUCCELLI, 1999, p. 369). Aqui o autor estrutura sua reflexão a partir dos trabalhos de Georg Simmel e Erwin Goffman, da chamada "Escola de Chicago", e de Alain Tourraine e Anthony Giddens.

A matriz da racionalização, escolhida como pano de fundo para este trabalho, se articula a partir de duas concepções básicas, já presentes em seu autor "fundador", Max Weber, mas que aparecem nos demais autores da matriz (Norbert Elias, Herbert Marcuse, Michel Foucault e Jürgen Habermas) e que irão também se manifestar em suas obras. A primeira dessas concepções é vista por Martuccelli como possuindo uma natureza "genética" e "diacrônica", e busca entender a especificidade produzida pelas sociedades ocidentais ao desenvolverem uma forma específica de racionalismo que lhes permitiu um controle (maîtrise) crescente do mundo. A segunda, de caráter "sincrônico", refere-se eminentemente ao estado social, às estruturas e à dinâmica da vida contemporânea observada pelos autores em seus respectivos momentos de vida, ou seja, aos efeitos do controle crescente do mundo sobre a vida dos indivíduos.

É exatamente a partir dessa segunda concepção que vários dos autores da matriz da racionalização irão manifestar uma profunda inquietação, no sentido de avaliar a possibilidade de emancipação humana capaz de se opor à lógica de racionalização dominante que, muitas vezes, se faz opressiva e alienante.

A proximidade entre as concepções associadas à matriz da racionalização e ao campo dos estudos organizacionais é evidente, na medida em que são as organizações os instrumentos utilizados para o controle do mundo a partir do controle dos indivíduos. Dessa forma, por tratar de temas centrais para o estudo das organizações de uma forma mais imediata, mais direta que as demais matrizes apresentadas pelo 
autor, a matriz da racionalização foi selecionada como um referencial mais promissor para a análise que se segue. Para realizar os objetivos desse artigo, destacaremos as contribuições de Habermas (1987a, 1987b, 2001), pois nelas podem-se observar as tentativas de desfazer uma tendência unidimensional imposta à racionalização pela concepção weberiana e buscar outra via de compreensão da racionalização dentro da modernidade, visando a emancipação e o esclarecimento. Mesmo concentrando-nos nas contribuições de um autor, acreditamos ser proveitosa a manutenção da noção de matriz da racionalização como pano de fundo de nossa análise, pelas possibilidades analíticas que proporcionam as suas concepções básicas apontadas acima (natureza diacrônica e sincrônica da noção de racionalização), que, certamente, ainda não foram esgotadas no campo dos estudos organizacionais.

Habermas (2001, p. 137) identifica três formas de interesses que constituem o conhecimento: técnico, prático e emancipatório. Relacionando esses três tipos de interesses com as três regras lógicometodológicas, o autor coloca que...

[...] no exercício das ciências empírico-analíticas, imiscui-se um interesse técnico de conhecimento; no exercício das ciências histórico-hermenêuticas, intervém um interesse prático do conhecimento e, no posicionamento das ciências de orientação crítica, está implicado aquele interesse emancipatório do conhecimento.

Nas ciências empírico-analíticas, o conhecimento técnico está relacionado com a construção de teorias e sua comprovação crítica. Tratase do interesse no controle da natureza e do mundo objetivo, visando a reprodução material da vida humana, que é exercido por um tipo de ação denominado técnico-instrumental. Ludmer et al (2002, p. 3) relacionam esse tipo de conhecimento com tecnologia da informação (TI), apontando as aplicações de TI como suporte aos processos organizacionais. Para os autores, "este tipo de conhecimento tem uma orientação de engenharia (design) e focaliza-se em teorias de desenvolvimento, métodos e práticas que ajudam na melhoria das organizações, das aplicações da tecnologia da informação e das vidas das pessoas que as utilizam". Campos (2007), adotando outra linha teórica, reforça a necessidade de se buscar "abordagens mais críticas, mais descritivas e menos normativas" ao se lidar com a gestão do conhecimento.

As ciências histórico-hermenêuticas obtêm seu conhecimento por outro enquadramento metodológico, unindo interpretação com aplicação. Para Habermas (2001, p. 138), a compreensão do sentido dirige-se, segundo a sua estrutura, para o possível consenso dos agentes no âmbito de um autocompreensão transmitida, o que chama de interesse prático de conhecimento. Em TI, Ludmer et al (2002, p. 4) colocam que o "foco é a interpretação e o mapeamento dos significados que os atores 
organizacionais constroem sobre a apropriação e uso da TI e as relações sociais que eles desempenham como resultado desses significados".

Habermas (2001, p. 140) afirma que o conhecimento emancipatório é oriundo de "enquadramentos metodológicos que estabelecem o sentido da validade desta categoria de enunciados críticos avalia-se pelo conceito da auto-reflexão", e liberta o sujeito de abstrações consideradas falsamente como reais. Com relação aos sistemas de informação, Ludmer et al (2002, p. 4) destacam que o foco do conhecimento emancipatório "é dirigido para a análise crítica e dialética de pressupostos teóricos, ordenações de valores e pressupostos correntes sobre tecnologias da informação e gestão e uso das mesmas nas organizações".

Para Habermas (1987a, 2001), o cerne da questão ideológica na modernidade consiste na primazia e no domínio da ação técnicainstrumental e do conhecimento empírico sobre o interesse prático e sobre o interesse pela emancipação humana. Para Habermas (1987a), nem mesmo o marxismo, uma das mais contundentes teorias críticas da modernidade, esteve livre do mais importante viés ideológico da modernidade, ou seja, o de reduzir a práxis à técnica. Foi necessário, de acordo com o autor, um resgate do caráter crítico do marxismo com vistas a rever o paradigma da produção nele embutido, de forma a que a síntese humana não seja mais exclusivamente pensada como realização do trabalho, mas que possa ser incluída uma perspectiva da interação, ou seja, do interesse prático. Nesse sentido, a teoria da ação comunicativa (HABERMAS, 1987b) não pretende excluir o interesse técnico-instrumental do processo de emancipação humana. Isto é, a razão instrumental não é vista exclusivamente como um fator de dominação; o núcleo da questão ideológica não se localiza, de acordo com Habermas e em discordância com Adorno, Horkheimer e Marcuse, na razão instrumental em si, mas na sua extensão a outras esferas de decisão racional.

A questão ideológica da modernidade apontada por Habermas consiste no deslocamento do interesse técnico-instrumental de seu âmbito (o sistema econômico e estatal) e na usurpação das funções do interesse prático, dominando-o. Isso significa que a razão e a ação instrumental ocupam o lugar da razão e ação comunicativa, cuja função consiste na interação baseada no entendimento. Para Habermas (1987b), os sistemas são instituições definidas pela capacidade de responder a exigências funcionais impostas pelo meio. O mundo da vida consiste nas formas integradas de vida social por meio de normas consensualmente aceitas pelos participantes. Sua racionalização possibilita a diferenciação de subsistemas autônomos, abrindo o horizonte para a emancipação. 0 sistema e o mundo da vida ocupam posições diferentes e complementares na reprodução da sociedade. O sistema é responsável pela reprodução material e o mundo da vida pela reprodução simbólica. Assim, a evolução do sistema corresponde ao aumento de sua capacidade de controle, enquanto que a evolução do mundo da vida corresponde ao aperfeiçoamento da capacidade comunicativa e da prática do entendimento. A complementaridade entre sistema e mundo da vida reside na seguinte constatação: o aumento da complexidade sistêmica 
exige uma institucionalização dos novos níveis de integração sistêmica, por conseguinte, um desenvolvimento da competência comunicativa e da prática de entendimento. Habermas defende a tese da primazia do mundo da vida e da reprodução simbólica em relação ao sistema, indicando que novas etapas da diferenciação sistêmica só podem ser efetivas quando a racionalização do mundo da vida tenha atingido um nível correspondente.

As formas de conhecimento identificadas encontram representação no campo de sistemas de informação. Conforme aponta Ludmer et al (2002), maior ênfase tem sido dada à forma de conhecimento técnico. Em sua pesquisa não foi possível encontrar nenhum artigo do ENANPAD que tratou dos assuntos a partir do conhecimento prático ou emancipatório, apesar de dois ou três trabalhos analisados fazerem referência à literatura que desafia o paradigma dominante. Este é, sem dúvida, um alerta e uma oportunidade de efetivas contribuições teóricas e práticas para todos envolvidos no campo de sistemas de informação, e o método de análise que propomos nesse trabalho é apresentado como uma perspectiva alternativa de produção de conhecimento. Trata-se do método de análise dialético que passaremos a descrever a seguir.

\section{Método de análise dialético}

Benson (1977, p. 2) vê a teoria dialética como uma maneira de explicar o "fundamento empírico das teorias da organização convencionais porque lida com os processos sociais que as teorias convencionais ignoram". A abordagem dialética é eminentemente processual, pois permite colocar o processo pelo qual os arranjos organizacionais são construídos sob o enfoque principal da análise. A teoria dialética "oferece uma explicação dos processos envolvidos na produção, a reprodução, e a destruição de formas organizacionais particulares". Em suas considerações, apresenta certo fracasso da sociologia das organizações em ser crítica, tendendo a manter as construções teóricas no campo e a afirmar as realidades presentes nas organizações.

A análise organizacional tem sido marcada por questões administrativas, pois, segundo Benson (1977, p. 3), as abordagens utilizadas combinam com posições metodológicas "que aceitam não criticamente os arranjos organizacionais existentes e adaptando-os aos interesses de elites administrativas". Farjoun (2002, p. 850) destaca que, pela natureza da análise dialética, não considera os arranjos sociais como sendo permanentes ou autoevidentes. Seu foco em uma disputa contínua entre forças opostas ajuda a explicar tanto a persistência como a mudança.

Em seu artigo amplamente referenciado, Benson (1977) propõe uma abordagem dialética para o estudo das organizações. Para ele, as organizações complexas foram estudadas a partir de teorias racionais e funcionalistas. Lyng e Kurtz (1985, p. 902) comentam sobre pesquisadores em burocracia que têm se voltado para além dos modelos racionais tradicionais, em direção a perspectivas que enfatizam as 
contradições na estrutura organizacional, por distorções de procedimentos racionais oriundos de ações políticas orientadas por interesses.

A teoria dialética tem suas bases em Hegel, em sua visão de um mundo pluralista. Mas Benson (1977, p.1) utilizou as bases do materialismo dialético de Marx para desenvolver sua concepção de análise dialética, pois considera a organização como um "fenômeno concreto e multi-nivelado, cercado por contradições que continuamente enfraquecem suas características explícitas". Na concepção dialética, o mundo está em contínuo estado de mudança e não existem arranjos permanentes; na realidade existem padrões temporários e arbitrários e que devem ser considerados como uma entre muitas possibilidades. Na análise dialética procura-se observar a transformação desses arranjos em novas combinações, envolvendo a busca "por princípios fundamentais que respondem pelo aparecimento e dissolução de ordens sociais específicas" (BENSON, 1977, p.4). A análise dialética deve ser conduzida observandose quatro princípios básicos: construção e produção social, totalidade, contradição, e práxis.

Construção e produção social: O compromisso ontológico básico enfatiza a produção social: "pessoas produzem o mundo social e são, por sua vez, produzidas por ele" (BENSON, 1983, p. 332). A transformação do mundo social se dá a partir das interações entre as pessoas, construindose padrões sociais e, eventualmente, arranjos institucionais, que são continuamente modificados ou substituídos. Esses arranjos sociais têm origem nas atividades cotidianas e a "produção da estrutura social é guiada e restringida pelo contexto" (BENSON, 1977, p.4).

Para Feldman (2000, p. 624), as organizações são trazidas para a existência através de relações sociais de produção, em que o poder exercido pela elite gerencial é usado para reproduzir certos arranjos sociais e evitar que outros, novos, surjam à tona. Também assume que esses arranjos são arbitrários e resultam de processos políticos e históricos que podem ser propositalmente alterados.

Totalidade: os fenômenos sociais devem ser estudados de forma relacional, observando-se a "inter-relação complexa e mútua pelos quais os componentes são construídos". Qualquer estrutura é vista como parte integrante de um todo maior, concreto, e nunca como um evento isolado ou abstrato. No entanto, apesar de olhar para o todo, ressalta a autonomia de suas partes. Para Filby e Wilmot (1988, p. 347), os atributos de um indivíduo (por exemplo, suas habilidades) são produto da totalidade das relações sociais.

Contradição: no processo de construção social encontram-se contradições, rupturas e inconsistências na vida social. Segundo Benson $(1977$, p. 6$), \ldots$

[...] as contradições sociais têm importantes efeitos sobre a produção. (1) Elas podem ocasionar deslocamentos e crises que ativam a procura por arranjos sociais alternativos; (2) elas podem se combinar de modo a facilitar ou de modo a dificultar mobilização social; (3) elas podem definir os limites da 
mudança dentro de um período particular ou dentro de um sistema determinado. A consciência destes limites pode permitir a última negação dos limites; mas no ínterim as contradições podem estar influindo bastante.

Sabherwal e Newman (2003) descrevem a produção da contradição como sendo a maneira pela qual a visão organizacional dominante é desafiada, em um processo essencialmente conflituoso.

Como exemplo de contradição, Leflave (1996, p. 24) se propõe a investigar a dimensão política das ações coletivas organizadas, onde o termo "político" se refere apenas às atividades envolvendo poder administrativo. Analisando a partir do que o autor denomina "dimensão ecológica das organizações", temos que: (a) as organizações somente existem como sistemas sociais individualizados se a elas são dadas existências autônomas como uma classe de sistema; (b) as organizações somente existem quando são reproduzidas por seres organizacionais em sociedades organizacionais: suas partes e ambientes constituídos por meio de processos organizacionais. O autor insiste na idéia de que essa constituição não é um fenômeno politicamente neutro, ela traz consigo processos de poder e dominação.

Reed (1984), ao desenvolver o conceito processual de administração, afirma que a natureza e o escopo do processo de negociação são assuntos controversos. O pluralismo penetrante que afeta a constituição e a construção do fenômeno organizacional, incluindo sua administração e o nosso conhecimento sobre ele, não pode ser negado ou ignorado. Brown e Schneck (1979) colocam que a análise política das organizações está diretamente relacionada à preservação de sistemas de poder, privilégio e prestígio organizacionais. Farjoun (2002) apresenta uma variante da análise dialética em que destaca o conflito como fonte de mudanças, focando especificamente nas contradições e nos atores sociais como principais fontes de contestação, e na dinâmica que os ligam às mudanças organizacionais.

Práxis: No compromisso axiológico da análise dialética, a preocupação é com a produção de mudança social em direção à práxis (BENSON, 1983, p. 335). Consiste na "reconstrução livre e criativa de arranjos sociais em base de uma análise debatida tanto dos limites como das possibilidades das formas sociais presentes" (BENSON, 1977, p. 6). Afirma o autor:

O compromisso da práxis é duplo, descritivo - isto é, daquelas pessoas que sob algumas circunstâncias podem se tornar agentes ativos reconstruindo suas próprias relações sociais e em última instância elas mesmas com base em análise racional - e ético - isto é, que as Ciências Sociais deveriam contribuir para o processo de reconstrução, para a liberação de potencial humano pela produção de formações sociais novas. 
Enfim, Benson (1983, p. 336) ressalta que a "visão dialética se constitui em uma base contínua para a reconstrução de teorias assim que novas realidades sociais são cuidadosamente examinadas", permitindo a crítica da realidade organizacional existente e a construção de alternativas futuras (BENSON, 1983).

Realizamos uma pesquisa em revistas acadêmicas internacionais dos últimos 30 anos (1978 a 2008) que empregam análise dialética, a partir da base de dados EBSCO. Destacaremos os resultados parciais sobre dois temas: pesquisa e conhecimento; e tecnologia, inovação e desempenho empresarial. Sobre o tema pesquisa e conhecimento, os artigos identificados foram os de Barton e Haslett (2007), Lewis e Grimes (1999), Gioia e Pitre (1990), Tsoukas (1989), Morgan (1981). São trabalhos que utilizam os métodos de estudo de caso, estudo ideográfico, metatriangulação e desenvolvimento teórico sobre assuntos como: paradigmas e teorias, estudos ideográficos, multiparadigmas, metatriangulação. Alguns empregam o nível de análise micro e outros o nível de análise macro. Ver original

Sobre o tema tecnologia, inovação e desempenho empresarial, os artigos identificados foram os de: DeLuca, Gallivan e Kock (2008), Sabherwal e Newman (2003), Drummond (2003), Slappendel (1996), Drazin (1990), Weill e Olson (1989), Robertson e Wind (1983), Fry (1982); Leatt e Schneck (1982), Ford e Schellenberg (1982), Strasser et al (1981), Blau e McKinley (1979). São trabalhos que utilizam os métodos de estudo de caso, desenvolvimento teórico, análise histórica e análise de conteúdo; também alguns empregando o nível de análise micro e outros o nível de análise macro. Observamos poucos trabalhos integrativos entre o nível de análise micro e o nível de análise macro.

O método de análise dialético é pouco empregado no campo de sistemas de informação, conforme revela nossa pesquisa bibliográfica sobre artigos que utilizam essa abordagem. A prática revela que não há nada mais contraditório, com rupturas e, na maioria das vezes, inconsistências, do que a implementação de um sistema de informação. Entendemos que o método dialético tem grandes contribuições a oferecer ao desenvolvimento do campo, tanto do ponto de vista de produção do conhecimento teórico como de sua prática. Reforçando e expandindo essa posição, em relação à ciência da informação, e ressaltando o aspecto metodológico, Azevedo (2004, p.1) observa que a aproximação da "hermenêutica com a dialética pode ser uma referência teóricometodológica para a área". O próximo tópico apresenta uma ilustração do uso do método.

\section{Uma Ilustração sobre conhecimento emancipatório}

Ngwenyama e Lee (1997) utilizaram o material empírico obtido do estudo de caso de uma empresa denominada HCP (MARKUS, 1994) para investigar como a riqueza da comunicação pode emergir do uso de e-mail por gerentes. O material empírico utilizado nesse trabalho baseia-se no estudo de caso de uma empresa brasileira denominada Sementes Selecta 
Ltda (MARINO; SCARE; ZYLBERSZTAJN, 2002). Embora o caso tenha sido desenvolvido para o estudo das redes de relacionamentos, definição de estratégias compartilhadas, padrões de concorrência e da estratégia competitiva na busca de lucro diferencial, o material será utilizado aqui para investigar a presença de conhecimento emancipatório relacionado com o uso da tecnologia da informação. Uma síntese do material empírico e os resultados da análise utilizando o método dialético encontram-se sumarizados no QUADRO 1 e no QUADRO 2.

A nossa análise fundamentou-se nos seguintes pressupostos metodológicos: a) a transformação do mundo social encontra-se enraizada nas características fundamentais da vida social humana. Segundo Benson $(1977,1983)$, trata-se do princípio da construção e produção social. Tal pressuposto se encontra também em Dachler e Wilpert (1978), Astley (1985) e Hatch (1997); b) a realidade é relacional e é possível estudá-la e compreendê-la considerando-se suas múltiplas interconexões. Segundo Benson (1977, 1983), trata-se do princípio da totalidade. Ver também Filby e Willmott (1988) e Seo e Creed (2002); c) o processo de construção social contém contradições, rupturas, inconsistências e incompatibilidades, e quebras radicais são possíveis devido a essas características. Segundo Benson (1977, 1983), trata-se do princípio da contradição. Ver também Eastman e Bailey (1998), Hatch (1997), Filby e Willmott (1988), Grimes e Cornwall (1987), Bresser e Bishop (1983), Mitroff; Mason e Barabba (1982); d) há processos de reconstrução livre e criativa de arranjos sociais na base de uma análise reflexiva debatida tanto sobre os limites quanto sobre as possibilidades alternativas de formas sociais presentes. Segundo Benson $(1977,1983)$, trata-se do princípio da práxis, ver também Bradbury e Mainemelis (2001) e Seo e Creed (2002). 


\section{QUADRO 1 Material empírico destacado para a investigação}

\begin{tabular}{|c|c|c|}
\hline Tópico & Páginas & Descrição \\
\hline $\begin{array}{l}\text { Natureza da } \\
\text { empresa }\end{array}$ & $3,17,20,24$ & $\begin{array}{l}\text { A Semente Selecta Ltda é uma empresa brasileira de médio porte e gestão } \\
\text { familiar, localizada no município de Goiatuba-GO, que produz, comercializa e } \\
\text { exporta soja e farelo de soja, presta serviços (financiamentos, } \\
\text { acompanhamento dos tratos culturais) e fornece insumos (sementes, } \\
\text { defensivos). Seus principais mercados nacionais para semente de soja são o } \\
\text { Estado de Goiás, parte do Mato Grosso, Minas Gerais e Maranhão. Os grãos } \\
\text { de soja são exportados para a Europa e a Ásia. O farelo de soja é vendido nos } \\
\text { Estados de Minas Gerais, São Paulo, Pará e Goiás. }\end{array}$ \\
\hline $\begin{array}{c}\text { Compromissos } \\
\text { e valores da } \\
\text { empresa }\end{array}$ & $3,12,13$ & $\begin{array}{l}\text { A Selecta é uma empresa que coordena uma rede produtiva. } \\
\text { Profissionalismo na produção de sementes e grãos. } \\
\text { A Rede de Relacionamentos é caracterizada pela inovação e pela busca do } \\
\text { novo (ALÉM..., 2002). } \\
\text { Os agricultores recebem estímulos constantes. } \\
\text { A Selecta diferencia o atendimento aos produtores. }\end{array}$ \\
\hline $\begin{array}{l}\text { Objetivos da } \\
\text { empresa }\end{array}$ & 4,5 & $\begin{array}{l}\text { Beneficiar e comercializar sementes de soja, farelo de soja e grãos de soja. } \\
\text { Não disputar o mercado com os concorrentes de grande porte, mas explorar as } \\
\text { vantagens que Ihe são cabíveis (por exemplo, realizando acompanhamento } \\
\text { técnico quando os concorrentes de grande porte não o fazem). }\end{array}$ \\
\hline Concorrência & 3,21 & $\begin{array}{l}\text { O mercado de grãos é um mercado de commodities, o setor mostra-se } \\
\text { concentrado nas mãos de quatro empresas multinacionais, o ABCD da soja } \\
\text { (ADM, Bunge, Cargill e Dreyfus) e algumas cooperativas (Coamo, Carol e } \\
\text { Comigo). }\end{array}$ \\
\hline $\begin{array}{l}\text { Estratégias da } \\
\text { empresa }\end{array}$ & $5,6,7,18,19$ & $\begin{array}{l}\text { São inúmeros os fatores que dão competitividade à Selecta, destacando-se: } \\
\text { atuação direta da diretoria / gerência executiva; histórico de reputação da } \\
\text { empresa; o pioneirismo no Centro-Oeste; a capacidade de antecipação às } \\
\text { mudanças externas proporcionada pelo dinamismo da organização; a prestação } \\
\text { de serviços; o acesso ao mercado de especialidades. } \\
\text { A empresa adora a estratégia de diferenciação e inovação. }\end{array}$ \\
\hline $\begin{array}{l}\text { Mecanismos } \\
\text { organizacionais }\end{array}$ & $\begin{array}{c}1,2,9,12,16 \\
19\end{array}$ & $\begin{array}{l}\text { "Dia de Campo" é um evento anual promovido pela Selecta que reúne } \\
\text { produtores nacionais e norte-americanos, parceiros comerciais e } \\
\text { representantes da sociedade (DIA, 2002). Coordenação da Rede de } \\
\text { Relacionamentos da Selecta. } \\
\text { Sistema de Identidade Preservada (Sistema IP) utilizado pela empresa para } \\
\text { coordenar produtores, segregar produtos com características diferenciadas e } \\
\text { desenvolver canais de distribuição. A co-especialização de atividades e a } \\
\text { dependência mútua fazem com que os adeptos do sistema IP não quebrem o } \\
\text { contrato, uma vez que seu produto não será valorizado pelos agentes externos } \\
\text { da rede, perdendo, assim, valor. } \\
\text { Sistema de Cultivo Convencional para a produção de sementes com } \\
\text { acompanhamento da Selecta durante todo o ciclo produtivo, e beneficiamento e } \\
\text { armazenamento dos grãos, planejamento e fornecimento de insumos, } \\
\text { desenvolvimento da produção por meio da visita de agrônomo. Nesse caso, o } \\
\text { produtor não é obrigado a vender a soja de volta para a Selecta. }\end{array}$ \\
\hline $\begin{array}{l}\text { Sistemas de } \\
\text { informação e } \\
\text { tecnologia da } \\
\text { informação }\end{array}$ & 9,13 & $\begin{array}{l}\text { A tecnologia de informação é importante na coleta e no tratamento dos dados } \\
\text { no processo de coordenacaão da Rede de Relacionamentos Selecta. } \\
\text { Com o Sistema IP a empresa utiliza intensivamente a tecnologia da informação } \\
\text { e as informações (Sistema medidores de geo-processamento - GPS, Sistemas } \\
\text { Gerenciadores de Banco de Dados, equipamentos para diagnósticos). } \\
\text { A informação produzida na Rede de Relacionamentos Selecta, mais do que os } \\
\text { contratos formais, é a garantia do bom funcionamento do Sistema IP. }\end{array}$ \\
\hline
\end{tabular}

Fonte: Elaborado a partir de MARINO; SCARE; ZYLBERSZTAJN (2002) 
QUADRO 2 - Duas imagens para a análise do material empírico

\begin{tabular}{|c|c|c|}
\hline Tópico & Páginas & Descrição \\
\hline $\begin{array}{l}\text { Sistema IP } \\
\text { como } \\
\text { dominação }\end{array}$ & $13,14,15,16$ & $\begin{array}{l}\text { A metáfora do Sistema IP como dominação ressalta as práticas da } \\
\text { Selecta em relação aos produtores por meio do sistema de } \\
\text { coordenação proporcionado por esse sistema. Parte-se da idéia de um } \\
\text { sistema como forma de representação de poder na sociedade moderna. } \\
\text { Aqui, a tecnologia de informação e os sistemas de informação são } \\
\text { instrumentos pelos quais é possível exercer a dominação unilateral e } \\
\text { realizar "a rastreabilidade total do produto" (MARINO, SCARE e } \\
\text { ZYLBERSZTAJN, 2002, p. 13). O conhecimento é concentrado e } \\
\text { dominado exclusivamente pela Selecta. }\end{array}$ \\
\hline $\begin{array}{c}\text { Sistema IP } \\
\text { como espaço } \\
\text { de produção } \\
\text { de acordos }\end{array}$ & $\begin{array}{l}13,14,15, \\
16\end{array}$ & $\begin{array}{l}\text { A metáfora do Sistema IP como espaço de produção de acordos } \\
\text { destaca uma forma diferente de relação entre os agentes - Selecta e } \\
\text { produtores. Estes se encontram organizados em rede com interligações } \\
\text { complexas de arranjos materiais e conceituais que produzem o tecido } \\
\text { das suas vidas cotidianas (ALVESSON e DEETZ, 1996, p. 201). Não se } \\
\text { destaca aqui apenas a dominação exercida pela Selecta em relação } \\
\text { aos produtores, mas, como afirma Habermas (1987b, p. 211), se aceita, } \\
\text { em algum nível, a autonomia dos agentes, a independência da cultura e } \\
\text { a transparência da comunicação. Por essa metáfora, a tecnologia da } \\
\text { informação e os sistemas de informação são veículos de passagem de } \\
\text { comunicação e cooperação, ou seja, segundo Marino, Scare e } \\
\text { Zylbersztajn (2002, p.12), instrumento para a realização do "ajuste } \\
\text { mútuo" e "interdependência recíproca". O conhecimento é } \\
\text { compartilhado, assim podemos pressupor que o banco de dados como } \\
\text { um todo seja de acesso exclusivo da Selecta. No entanto, por haver } \\
\text { ajuste mútuo e interdependência recíproca, uma parcela do do } \\
\text { conhecimento produzido pelo sistema pode ser incorporado também } \\
\text { pelos produtores. }\end{array}$ \\
\hline
\end{tabular}

Fonte: Análise a partir de MARINO; SCARE; ZYLBERSZTAJN (2002).

Para esta análise, realizamos os seguintes procedimentos metodológicos: a) reunir o material empírico para a investigação e construir o QUADRO 1; b) destacar idéias importantes para a análise pretendida e construir o QUADRO 2; c) definir as questões de trabalho mais detalhadas que orientaram a análise; e d) demonstrar o resultado da análise. Com base na visão de Habermas sobre a modernidade, podemos formular a seguinte questão de trabalho: há evidências da existência de conhecimento do tipo emancipatório?

Se considerarmos a imagem do Sistema IP como dominação, entende-se que não pode haver evidências de conhecimento emancipatório nesse sistema. Isso se deve não somente à completa dominação por parte da empresa, ao uso do seu poder absoluto, mas também ao fato de que as pessoas poderiam simplesmente não querer ser livres, rejeitando a perspectiva da libertação por causa das dificuldades que o exercício da liberdade pode acarretar.

Se considerarmos a imagem do Sistema IP como espaço de produção de acordos, podemos incorporar à análise as duas expressões: "ajuste mútuo" e "interdependência recíproca", indicando a possibilidade da existência de uma estratégia emergente que disputa espaço com a estratégia deliberada da empresa. O processo de negociação entre as estratégias emergente e deliberada indica a existência de um processo de auto-reflexão por parte dos produtores. Maior conhecimento deve ser 
desenvolvido sobre o significado das expressões "ajuste mútuo" e "interligações recíprocas" do ponto dos agentes. No entanto, se esses termos forem expressão de algum tipo de deformação ou deformações da divisão social do trabalho praticado pelos agentes, isso significa que tais deformações são incorporadas como contradição no processo de construção social e, portanto, elas podem, conforme Benson (1977), ocasionar deslocamentos e crises que ativam a procura por arranjos sociais alternativos; combinar-se de modo a facilitar ou de modo a dificultar a mobilização social; e definir os limites da mudança dentro de um período particular ou dentro de um sistema determinado.

\section{Considerações finais}

Nesse artigo, tratamos da relação entre sistemas de informação e o conhecimento de interesse emancipatório. Iniciamos com uma breve introdução e apresentamos as noções de modernidade, racionalização e conhecimento, utilizando especificamente as idéias de Jürgen Habermas. Modernidade, racionalidade e construção de conhecimento são noções importantes para a discussão de temas relacionados à sociedade e às organizações. Normalmente não são assuntos muito discutidos no campo de Sistemas de Informação. Nesse trabalho, essas noções constituíram-se num contexto pelo qual foi possível propor e ilustrar a utilização do método de análise dialético, no tópico três.

Utilizamos o material empírico do estudo de caso da Semente Selecta Ltda para ilustrar a utilização do método de análise dialético, por meio do qual pudemos ressaltar os princípios de construção e produção social, totalidade, contradição e práxis, dentro das possibilidades que 0 próprio estudo de caso proporcionou.

O método de análise dialético mostrou-se adequado para a análise da situação, visto que se tinha como objetivo o desenvolvimento de conhecimento de interesse emancipatório, conforme descrito. Os princípios fundamentais de Benson (1977) são pertinentes às características do tipo de conhecimento emancipatório, pois são adequados à análise de conhecimentos institucionais, além de serem relativamente simples para a análise de organizações complexas.

A principal força do método de análise dialético é a sua simplicidade de aplicação, embora exija um trabalho de deslocamento de modelo mental realizado por parte do pesquisador. Esse deslocamento pode ser desenvolvido empregando-se a noção de metáfora, conforme foi empregada nesse trabalho, inspirando-se em Morgan (1996).

Uma das limitações dessa investigação consiste no fato do próprio estudo de caso não apresentar dados que possibilitem uma discussão mais aprofundada sobre interesses dos conhecimentos e a relação com sistemas de informação e tecnologia da informação. Outra limitação do estudo diz respeito à impossibilidade de acesso a fontes primárias de dados.

Observamos que a análise dialética fundamenta-se na visão de mundo dos pesquisadores que a utilizam. Esse fato tem sido apontado 
como aspecto positivo quando o objetivo é a exploração em nível de análise micro.

Entendemos que a forma de expandir o conhecimento sobre o conhecimento emancipatório, e a utilização do método de análise dialético, consiste em coletar os dados dirigidos para o tipo de análise, tanto em termos de conteúdo como também em termos de detalhamento. Futuras pesquisas poderão ser realizadas nesse sentido. Indica-se também a exploração de outras possibilidades de fundamentação teórica proporcionada pela noção de matriz da racionalização, destacando ou promovendo o diálogo entre outros autores. Essa via de desenvolvimento de futuras pesquisas impõe consideráveis desafios teóricos e práticos, com a possibilidade de efetivas contribuições ao campo de sistemas de informação.

\section{Referências}

AZEVEDO, M. A. Informação e interpretação: uma leitura teóricometodológica. Perspectivas em Ciência da Informação, v. 9, n. 2, p. 122133, jul/dez 2004.

ALÉM do horizonte. Safra: Revista do Agronegócio. Abr. 2002. Disponível em: <http://www.revistasafra.com.br/2002-04/pan01.htm>. Acesso em: 28 fev. 2004.

ALVESSON, M.; DEETZ, S. Critical theory and postmodernism approaches to organizational studies. In: CLEGG, S. R.; HARDY, C.; NORD, W. R (Orgs.). Handbook of organization studies. London: Sage Publication, 1996, cap. 1.7 , p. 191-217.

ASTLEY, W. G. Administrative science as socially constructed truth. Administrative Science Quarterly, v. 30, n. 4, p. 497-513, dec. 1985.

BARTON, J.; HASLETT, T. Analysis, synthesis, systems thinking and the scientific method: rediscovering the importance of open systems. Systems Research \& Behavioral Science, v. 24, n. 2, p. 143-155, mar/apr. 2007.

BENSON, J. K. A Dialectical method for the study of organization. In: MORGAN, G. (Ed.) Beyond Method: strategies for social research. Newbury Park: Sage, 1983. p. 331-346.

Organizations: a dialectical view. Administrative Science Quarterly, v. 22, n. 1, p.1-21, mar. 1977.

BLAU, J. R.; McKINLEY, W. Ideas, complexity, and innovation. Administrative Science Quarterly, v. 24, n. 2, p. 200-219, June 1979.

BRADBURY, H.; MAINEMELIS, H. Learning History and Organizational Praxis. Journal of Management Inquiry, v. 10, n. 4, p. 340-358, dec. 2001.

BRESSER, R. K.; BISHOP, R. C. Dysfunctional effects of formal planning: two theoretical explanations. Academy of Management Review, v. 8, n. 4, p. 588-623, Oct. 1983. 
BRONNER, S. E. Da teoria crítica e seus teóricos. Campinas: Papirus, 1997.

BROWN, J. L.; SCHNECK, R. A structural comparison between Canadian and American industrial organizations. Administrative Science Quarterly, v. 24, n. 1, p. 24-47, mar. 1979.

CAMPOS, L. F. B. Análise da nova gestão do conhecimento: perspectivas para abordagens críticas. Perspectivas em Ciência da Informação, v. 12, n. 1, p. 104-122, jan/abr. 2007.

CASTELLS, M. A sociedade em rede. $3^{\text {a }}$ ed. São Paulo: Paz e Terra, 1999.

DACHLER, H. P.; WILPERT, B. Conceptual dimensions and boundaries of participation in organizations: a critical evaluation. Administrative Science Quarterly; v. 23, n. 1, p. 1-39, mar. 1978.

DIA de campo. Revista Negócios, n. 43, 2002. Disponível em: $<$ http://www.revistanegocios.com.br/ler artigo.asp?idartigo=123\#>. Acesso em: 28 fev. 2004.

DELUCA, D.; GALLIVAN, M. J.; KOCK, N. Furthering information systems action research: a post-positivist synthesis of four dialectics. Journal of the Association for Information Systems, v. 9, n. 2, p. 48-72, Feb. 2008.

DRAZIN, R. Professional and innovation. Journal of Management Studies, v. 27, n. 3, p. 245-264, May 1990.

DRUMMOND, $\mathrm{H}$. Did Nick Leeson have an accomplice? The role of information technology in the collapse of Barings Bank. Journal of Information Technology, v. 18, n. 2, p. 93-101, June 2003.

EASTMAN, W.; BAILEY, J. R. Mediating the fact-value antinomy: patterns in managerial and legal rhetoric, 1890-1990. Organization Science, v. 9, n. 2, p. 232-243, Mar./Apr. 1998.

FARJOUN, M. The dialectics of institutional development in emerging and turbulent fields: the history of pricing conventions in the on-line database industry. Academy of Management Journal, v. 45, n. 5, p. 848-875, Oct. 2002.

FELDMAN, S. Management ethics without the past: rationalism and individualism in critical organization theory. Business Ethics Quarterly, v. 10, n. 3, p. 623-644, July 2000.

FILBY, I.; WILLMOTT, H. Ideologies and contradictions in a public relations department: the seduction and impotence. Organization Studies, v. 9, n. 3, p. 335-349, 1988.

FORD, J. D.; SCHELLENBERG, D. A. Conceptual issues of linkage in the assessment of organizational performance. Academy of Management Review, v. 7, n. 1, p. 49-58, Jan. 1982.

FRY, L. W. Technology-structure research: three critical issues. Academy of Management Journal, v. 25, n. 3, p. 532-573, sep. 1982. 
GIDDENS, A. As conseqüências da modernidade. $2^{\underline{a}}$ ed. São Paulo: UNESP, 1991.

GIDDENS, A. A vida em uma sociedade pós-tradicional. In: BECK, $U$, GIDDENS, A e LASCH, S. Modernização reflexiva. São Paulo: UNESP, 1997, cap. 2, p. 73-133.

GIDDENS, A. Modernidade e identidade. Rio de Janeiro: Jorge Zahar, 2002.

GIOIA, D. A.; PITRE, E. Multiparadigm perspectives on theory building. Academy of Management Review, v. 15, n. 4, p. 584-602, Oct. 1990.

GRIMES, A. J.; CORNWALL, J. R. The disintegration of an organization: a dialectical analysis. Journal of Management, v. 13, n. 1, p. 69-86, Spring 1987.

HABERMAS, J. Conhecimento e interesse. Rio de Janeiro: Editora Guanabara, 1987a.

. Teoria de la accion comunicativa. 2 tomos. Madri: Tauros, 1987b.

. Técnica e ciência como "ideologia". Lisboa: Edições 70, 2001.

$\mathrm{HATCH}, \mathrm{M}$. J. Irony and the social construction of contradiction in the humor of a management team. Organization Science, v. 8, n. 3, p. 275288, May/June 1997.

KUHN, T. S. A estrutura das revoluções científicas. São Paulo: Perspectiva, 2001.

LAUDON, K. C.; LAUDON, J. P. Management information system. $10^{\text {th }}$. ed. Upper Saddle River, N. J.: Prentice Hall, 2007.

LEATT, P.; SCHNECK, R. Technology, size, environment, and structure in nursing subunits. Organization Studies, v. 3, n. 3, p. 221-242, 1982.

LEFLAIVE, $\mathrm{X}$. Organizations as structures of domination. Organization Studies, v. 17, n. 1, p. 23-47, 1996.

LEWIS, M. W.; GRIMES, A. J. Metatriangulation: Building Theory from Multiple Paradigms. Academy of Management Review, v. 24, n. 4, p. 672691, oct. 1999.

LUDMER, G. et al. Conhecimento emancipatório em sistemas de informação no Brasil: uma avaliação da produção acadêmica. In: ENCONTRO NACIONAL DOS PROGRAMAS DE PÓS-GRADUAÇÃO EM ADMINISTRAÇÃO - ENANPAD, 26., 2002, Salvador, Anais..., Salvador, ANPAD, 2002. CD Rom.

LYNG, S. G.; KURTZ, L. R. Bureaucratic insurgency: the vatican and the crisis of modernism. Social Forces, v. 63, n. 4, p. 901-922, June 1985.

MARINO, M. K.; SCARE, R. F.; ZYLBERSZTAJN, D. Selecta: diferenciação e coordenação de redes no agribusiness brasileiro. Seminário PENSA de Agronegócios, PENSA - Programa de Estudos dos Negócios do Sistema 
Agroindustrial, março de 2002. Disponível em: < http://www.fia.com.br/pensa/home.htm >. Acesso em: 28 fev. 2004.

MARKUS, M. L. Eletronic mail as the médium of managerial choice. Organization Science, v. 5, n. 4, p. 502-527, 1994.

MARTUCCELLI, D. Sociologies de la modernité. Paris: Gallimard, 1999.

MITROFF, I. I.; MASON, R. O.; BARABBA, V. P. Policy as argument: a logic for ill-structured decision problems. Management Science, v. 28, n. 12, p. 1391-1404, Dec. 1982.

MORGAN, G. Imagens da organização. São Paulo: Atlas, 1996.

MORGAN, G. The schismatic metaphor and its implications for organizational analysis. Organization Studies, v. 2, n. 1, p. 23-44, 1981.

NGWENYAMA, O. K.; LEE, A. S. Communication richness in electronic mail: critical social theory and the contextuality of meaning. MIS Quarterly, v. 21, n. 2, p. 145-167, June 1997.

REED, M. I. Management as a social practice. Journal of Management Studies, v. 21, n. 3, p. 272-285, july. 1984.

ROBERTSON, T. S.; WIND, Y. Organizational cosmopolitanism and innovativeness. Academy of Management Journal, v. 26, n. 2, p. 332-338, June 1983.

SABHERWAL, R.; NEWMAN, $M$. Persistence and change in system development: a dialectical view. Journal of Information Technology, v. 18, n. 2, p. 69-93, June 2003.

SEO, M. G.; CREED, W. E. Institutional contradictions, praxis, and institutional change: a dialectical perspective. Academy of Management Review, v. 27, n. 2, p. 222-248, Apr. 2002.

SLAPPENDEL, C. Perspectives on innovation in organization. Organization Studies, v. 17, n. 1, p. 107-129, 1996.

STRASSER, S. et al. Conceptualizing The Goal And System Models Of Organizational Effectiveness. Journal of Management Studies, v. 18, n. 3, p. 321-340, July 1981.

TOURAINE, A. Crítica da modernidade. Petrópolis: Vozes, 1994.

. Uma visão crítica da modernidade. In: SOARES, M. S. A (Org.). A modernidade: Coleção Caderno de Sociologia. Porto Alegre: UFRGS/PPGS, v. 5, n. 5, p. 32-41, 1993.

TSOUKAS, $\mathrm{H}$. The validity of idiographic research explanations. Academy of Management Review, v. 14, n. 4, p. 551-561, Oct. 1989.

TURBAN, E.; MCLEAN, E.; WETHERBE, J. Information technology for management. 3a. ed. New York: John Wiley \& Sons, 2002.

WEILL, P.; OLSON, M. H. An assessment of the contingency theory of management information systems. Journal of Management Information Systems, v. 6, n. 1, p. 59-86, Summer 1989. 